\title{
Larval supply: a good predictor of recruitment of three species of reef fish (Pomacentridae)
}

\author{
M. J. Milicich", , M. G. Meekan ${ }^{1,2}$, P. J. Doherty ${ }^{1,2}$ \\ 'Australian Institute of Marine Science, PMB 3, Townsville, Queensland, Australia 4810 \\ ${ }^{2}$ School of Environmental Studies, Griffith University, Nathan, Brisbane, Queensland, Australia
}

\begin{abstract}
This study investigated the hypothesis that recruitment variations of coral reef fish directly reflect variations in larval supply. At Lizard Island, northern Great Barrier Reef, larval supply and recruitment of 3 species of damselfish (Pomacentrus amboinensis, P. nagasakiensis and Dischistodus perspicillatus) were estimated from light trap and patch reef collections respectively, over 2 consecutive recruitment seasons, in each of 3 habitats. Comparison of these patterns pooled over species and seasons revealed a good overall correlation between larval supply and early recruitment levels, suggesting that pre-settlement distributions may be the major determinant of early recruitment patterns despite mediating influences from factors such as habitat selection and post-settlement mortality. This result also supports the use of broad recruitment surveys to estimate year-class strength and to hindcast patterns in larval supply. When analysed at the individual species/season level, the abundance of recruits on patch reefs and the abundance of larvae in light trap collections were also significantly correlated, with the exception of one species ( $P$. amboinensis) during one season $(1989 / 90)$. When the level of comparison was further narrowed to analyse correlations between preand post-settlement fish of individual species in each season, within each habitat, only 7 significant relationships were detected out of a possible $18 \mathrm{habitat} / \mathrm{species}$ combinations. The power of these tests was relatively high $($ mean $=0.846 ; \mathrm{SE}=0.03$ ). These relationships provide some evidence for habitat selection suggesting that $P$. amboinensis preferred the leeward habitat, while $D$. perspicillatus preferred the windward habitat.
\end{abstract}

\section{INTRODUCTION}

Variable replenishment is characteristic of reef fish populations in all tropical oceans (see reviews by Doherty \& Williams 1988, Doherty 1991). Despite widespread documentation of this phenomenon, the recruitment of juveniles to benthic populations at any given place or time remains an unpredictable event and there is still much uncertainty about the causes of this variability. Part of the difficulty arises because recruitment is the end result of a complex chain of events involving spawning, dispersal and survival of propagules within the planktonic environment, habitat selection during settlement, and post-settlement survival of juveniles in the reef environment.

Some linkages in this chain are more tractable, and hence have been studied more intensively than others. For example, the pelagic stages are technically difficult to observe and remain the least understood whereas the relative ease of making visual surveys in reef environments means that a great deal of attention has been paid to the recruitment patterns of species. In general, these surveys have emphasized the unpredictable and episodic nature of recruitment measured over all spatial scales and much of this variability has been attributed without direct evidence to the influence of planktonic processes operating between spawning and settlement.

Robertson et al. (1988) attempted to quantify the influence of these planktonic processes by contemporaneous measurements of spawning and recruitment in a Caribbean damselfish. They found that spawning output exhibited lunar rhythms which were detectable in average monthly recruitment data. Without pooling, however, monthly recruitment episodes were found to be shorter and more variably timed than the equivalent spawning cycles. Back-calculating the hatching and settlement dates of successful recruits from otolith 
records, Robertson et al. (1988) found that individual recruitment episodes were generally formed from larvae that had hatched within a few consecutive days and had settled together in similar order, after a relatively fixed larval period. The magnitude of monthly recruitment showed 4 times more variability than the production cycles that generated them and the magnitude of settlement in any month could not be predicted from the spawning activity in the previous month.

Although equivalent studies have not yet been published for any fish from the Great Barrier Reef, Doherty (1983a) reported regular semi-lunar rhythms in spawning by 2 damselfish and various authors have reported on the irregular and unpredictable nature of recruitment (Williams \& Sale 1981, Doherty 1983b, Williams 1983, Sale et al. 1984a, Sale 1985). While it is natural to assume that this independence arises from stochastic variation in the mortality and transport processes which determine larval supply, habitat selection and post-settlement mortality are other confounding processes which could add significantly to overall variation.

Historically, there have been few studies based on systematic sampling of tropical ichthyoplankton and the exceptions have generally been concerned with broad-scale patterns rather than local variations in larval supply (e.g. Leis \& Miller 1976, Houde et al. 1979, Leis 1986, Leis et al. 1989). More recently, it has become obvious that conventional plankton surveys are limited in their ability to deliver information on larval supply, as the late pre-settlement stages of many coral reef fish are agile nekton and are poorly sampled by filtration devices (Choat et al. in press).

The research literature on larval fish contains a number of anecdotal references to older forms being harvested around night-lights (Leis \& Rennis 1983, Thresher 1984). Doherty (1987) incorporated this principle into a design for a submersible automated light trap and these devices have since been tested in the field on several occasions and over long periods (Milicich 1988, 1992, Choat et al. in press, S. R. Thorrold unpubl.). Results suggest that light traps act as efficient collectors of late-stage larvae, from a wide range of taxa. As these larvae are ready or nearly ready to settle (Thorrold \& Milicich 1990), light traps are particularly suited to investigations of larval supply. In addition, the automation of these devices, which permits extended simultaneous operation (Doherty 1987), means that larval supply can be monitored at a number of locations and directly related to recruitment patterns observed at the same scale.

As a first step to understanding and eventually to predicting recruitment events, we have investigated the simple hypothesis that recruitment variation directly reflects variation in larval supply. Excluding sampling error, an absence of simple correlations would imply that processes operating at or shortly after settlement were important modifiers of initial replenishment patterns and, depending on the degree of modification, may be the most important determinants of recruitment. The aim of the present study was to distinguish between these 2 alternatives by describing the relationships between the distributions of pre-and post-settlement fish for 3 species of tropical damselfish (family: Pomacentridae).

\section{METHODS}

Sampling was conducted over 2 consecutive breeding seasons (summer 1988/89 and 1989/90) around Lizard Island, a continental island with a fringing coral reef and lagoon, in the northern section of the Great Barrier Reef. Pre- and post-settlement fish distributions were described for 3 species, Pomacentrus amboinensis, Pomacentrus nagasakiensis and Dischistodus perspicillatus, in the windward, leeward and lagoonal habitats of the reef (Fig. 1). These habitats were defined by their exposure to the southeast trade winds which predominate throughout much of the year. Although light traps collect a far greater range of species than the 3 pomacentrids reported here, the logistic requirements of regularly censusing settled individuals restricted the comparison to these 3 species.

Pre-settlement iish distributions. In each habitat, 2 light traps were moored ca $250 \mathrm{~m}$ apart at a distance of between 300 to $500 \mathrm{~m}$ from the nearest reef margin in 18 to $23 \mathrm{~m}$ of water. Full details of trap design and operation are given in Doherty (1987). Traps were suspended from the surface so that their entrances were at a water depth of $1 \mathrm{~m}$ and they were moored to allow free swing with changing current flow. Fishing was conducted over three $1 \mathrm{~h}$ periods per night (21:00 to $22: 00 \mathrm{~h}, 24: 00$ to $01: 00 \mathrm{~h}, 03: 00$ to $04: 00 \mathrm{~h}$ ) which integrated and reduced any effect that time of night or tidal state may have had on catch rates. Traps were cleared daily from November to January in both years.

For the purposes of the present analysis, a representative time series of fish abundance was generated for each habitat by averaging across daily catches in replicate traps. This procedure assumed the 2 light traps in each habitat were acting as true replicates, i.e. their effective light fields did not overlap. Work by Milicich (1992) suggests that, under ideal conditions at Lizard Island, the maximum distance at which a fish may respond to the light source of the trap is ca $90 \mathrm{~m}$. Furthermore, comparison of daily catches among adjacent traps over 3 consecutive years suggests that temporal variations in catch rates are coherent among 
adjacent traps (Milicich 1988, 1992). Based on this evidence, we conclude that the 2 traps in each habitat were acting as replicates.

For most of the first season, only 1 trap was operational in the lagoonal habitat and in the second season, replicates were missing from windward and/or lagoonal localities for periods of up to a week. While these lapses of replication were obviously undesirable, the high precision associated with the light traps suggests that single traps will provide good time series of the magnitude of larval supply. Hence, trap failures were accommodated in the following manner. Where one trap failed in any habitat, the record from the remaining trap was used, instead of the pair average, to represent fish abundance for that habitat. If no data were available from a habitat on any one day, an estimated daily catch was derived by interpolation between points on the surrounding 2 days (this occurred on only 4 occasions). This was considered valid since catch rates of a wide range of taxa are significantly dependant on previous catches (i.e. autocorrelated) for at least the preceding 1 to $2 \mathrm{~d}$ (Milicich 1992). To err on the side of caution, we did not interpolate catch rates that were not bounded on either side by observed values; the single $3 \mathrm{~d}$ period that this applies to is identified as missing.

Post-settlement fish distributions. Recruitment of the 3 species to artificial patch reefs was monitored concurrently to the light trap study. These reefs were constructed of 3 Pocillopora coral heads, and each reef measured approximately $50 \times 50 \times 35 \mathrm{~cm}$. They were placed on sand at least $8 \mathrm{~m}$ from the reef margin within each of the windward, lagoonal and leeward habitats where light traps were anchored. In the first season (1988/89), 5 patch reefs were monitored at each of 3 sites within each habitat. Sites were separated by $500 \mathrm{~m}$ so that 2 of the sites were immediately adjacent to the anchored traps. In the second season (1989/90), the third site was eliminated from each habitat. In both seasons, fish from all of the patch reefs were collected at approximately weekly in- tervals, using the anaesthetic Quinaldine (TM) and handnets. Thus, recruitment in this study is defined as the abundance of fish within a week of settlement. Although the interval between settlement and collection was relatively short, Doherty \& Sale (1986) observed the loss of at least $25 \%$ of recently metamorphosed damselfish within $5 \mathrm{~d}$ of their first sighting. Thus, variations in post-settlement mortality at this scale have considerable potential to distort the initial patterns determined by larval supply.

Data analysis. Relative abundance patterns of presettlement fish caught by the light traps were analysed using time series analyses in the time domain. These analyses consisted of sets of pair-wise cross-correlation functions (CCFs) which were used to estimate how well the timing of larval supply was synchronised among habitats and among species. The CCFs were generated by computing Pearson correlation coefficients between 2 time series as 1 series was progressively shifted day by day across the other. This allowed significant correlations to be identified at a range of temporal lags between the 2 series. To reduce the chance of spurious coefficients (caused by significant auto-correlations within each series), all series were
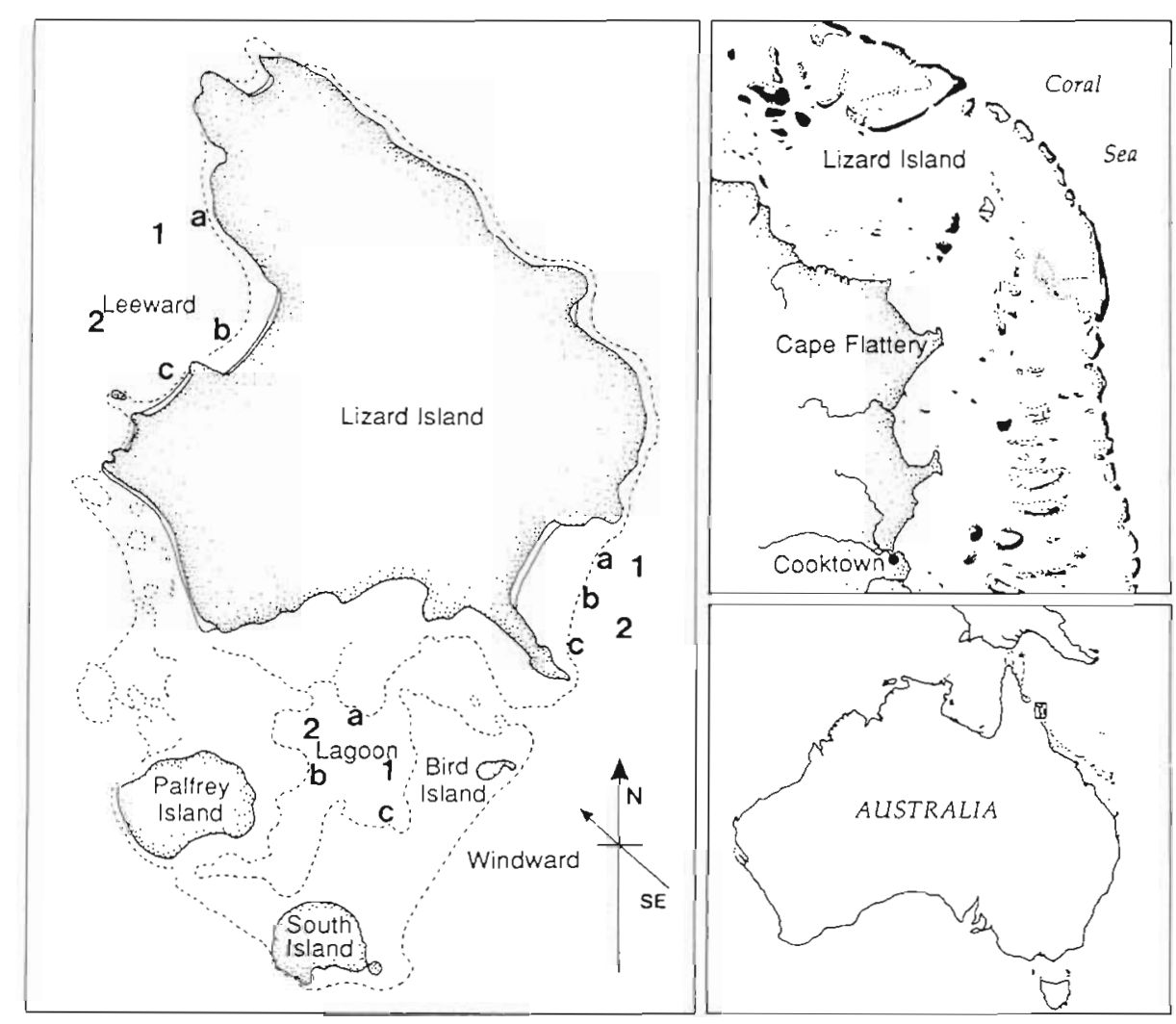

Fig. 1. Lizard Island, northern Great Barrier Reef, study site positions. Numbers refer to light trap sites and letters identify patch reef positions. Direction of the prevailing Trade Winds is identified by a compass arrow 
pre-filtered using a mixture of auto-regressive (AR) models (Chatfield 1984). Model AR (3 0 0) was used for 2 series from the first year: Pomacentrus amboinensis in the windward habitat and $P$. nagasakiensis in the leeward habitat. Model AR ( $\left.\begin{array}{lll}1 & 0 & 0\end{array}\right)$ was used for all other species/habitat combinations.

The regular sampling of post-settlement fish resulted in 10 weeks of data from each season. These time series were too short to analyse using the techniques outlined above, yet the data may be highly auto-correlated and this could artificially inflate test statistics (Thompson \& Page 1989). We computed weekly means for each habitat and inspected the auto-correlation functions (ACFs) of every combination of species and habitat to assess the level of autocorrelation present (Chatfield 1984). Significant auto-correlation was found only in the data from the first season, and this was removed by first-differencing each series before analysis (Box \& Jenkins 1976). To firstdifference a series, each value is subtracted from the following one to create a new series, i.e. $y_{t}=x_{t+1}-x_{t}$

Following Thompson \& Page (1989), we used tests based on the mean correlation $(\bar{r})$ and the largest eigenvalue of the first principal component $\left(\lambda_{1} / p\right)$ to detect dependance between 2 data sets. Tests were used to compare the independance of data sets among habitats for each species and conversely among species in each habitat. Test statistics were calculated for each comparison and compared to critical values generated from Monte Carlo simulations ( $\mathrm{n}=1000$, using $N(0,1), \rho=0)$. If the values of $\bar{r}$ and $\lambda_{1} / p$ were greater than the test statistics, the null hypothesis of independance between the 2 data sets was rejected.

Comparison of pre- and post-settlement distributions. To compare results from the 2 sampling strategies, daily catches from the light traps were accumulated into weekly blocks matching those of the regular collections of recruits from the patch reefs for each species/habitat combination. Subsequently, analysis was conducted to examine the relationship, in each season, between light trap catches and recruitment levels at the following scales:

(1) On data sets obtained by pooling across both species and habitats (2 comparisons: 2 year-classes). This multi-specific comparison was made to assess the overall generality of the relationship between larval supply and recruitment. As replenishment in many species is concentrated over specific parts of the season, the pooling procedure increased the number of replenishment events that could be used to investigate the relationship between supply and recruitment.

(2) On data sets for individual species pooled across habitats ( 6 comparisons: 2 year-classes $\times 3$ species). This comparison allowed the taxon-specific relationships between pre- and post-settlement distributions to be examined.
(3) On data sets for individual species/habitat combinations (18 comparisons: 2 year-classes $\times 3$ species $\times 3$ habitats). This small scale was used to identify the lowest level of resolution at which any relationship between larval supply and recruitment may be expected to persist. Power analyses were conducted on these regression models following Zar (1984).

\section{RESULTS}

\section{Pre-settlement fish distributions}

Time series plots of the raw data in both seasons of sampling reveal that for each species, occurrence of pre-settlement fish in the nearshore waters of Lizard Island was pulsed and episodic (Fig. 2). In the first season, the light traps caught a total of 3817 Dischistodus perspicillatus, 2547 Pomacentrus amboinensis and 666 $P$. nagasakiensis (sum of means across the 3 habitats). In the second season of sampling, catches of presettlement $P$. amboinensis (1391) and $D$. perspicillatus (420) were 45 and $89 \%$ lower than those of the year before, while numbers of $P$. nagasakiensis (671) showed little change.

In general, temporal patterns in the abundance of all 3 species of pre-settlement fish displayed high synchrony among the 3 habitats (Fig. 2). This is evidenced by the significant cross-correlation coefficients that were present at low lags, for most habitat combinations, within each species (Table 1). Exceptions occurred in both sampling years: catches of Pomacentrus amboinensis between the leeward and windward habitats were not synchronous, at low lags, during the first season (Table 1). A 3 d period of trap failure in the windward habitat during December (Days 43 to 45 ) added to the discordance among the habitats (Fig. 2). In the second season of sampling, asynchrony was again detected between the leeward and windward habitats, but for catches of Dischistodus perspicillatus. As in the first year, this appears to be the result of a period of low catches in the leeward habitat compared with both the lagoon and the windward habitats during November (Days 9 to 18). One month later this was reversed and catches from the leeward habitat reached their seasonal peak while windward catches were minimal or zero. Catches in the lagoon were intermediate between these 2 extremes.

The relative magnitude of catches among habitats followed species-specific patterns. The abundance of Pomacentrus amboinensis and Dischistodus perspicillatus varied among the habitats between the 2 sampling years indicating no consistent pattern in the relative magnitude of larval supply to each habitat. In 

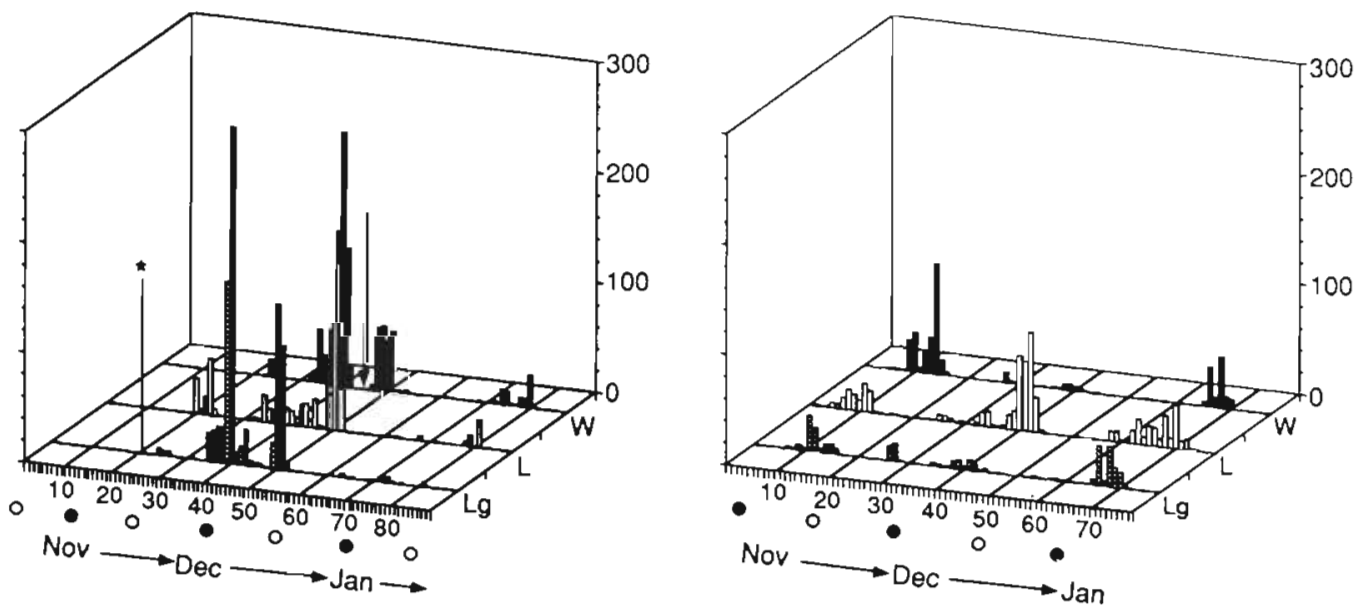

P. nagasakiensis
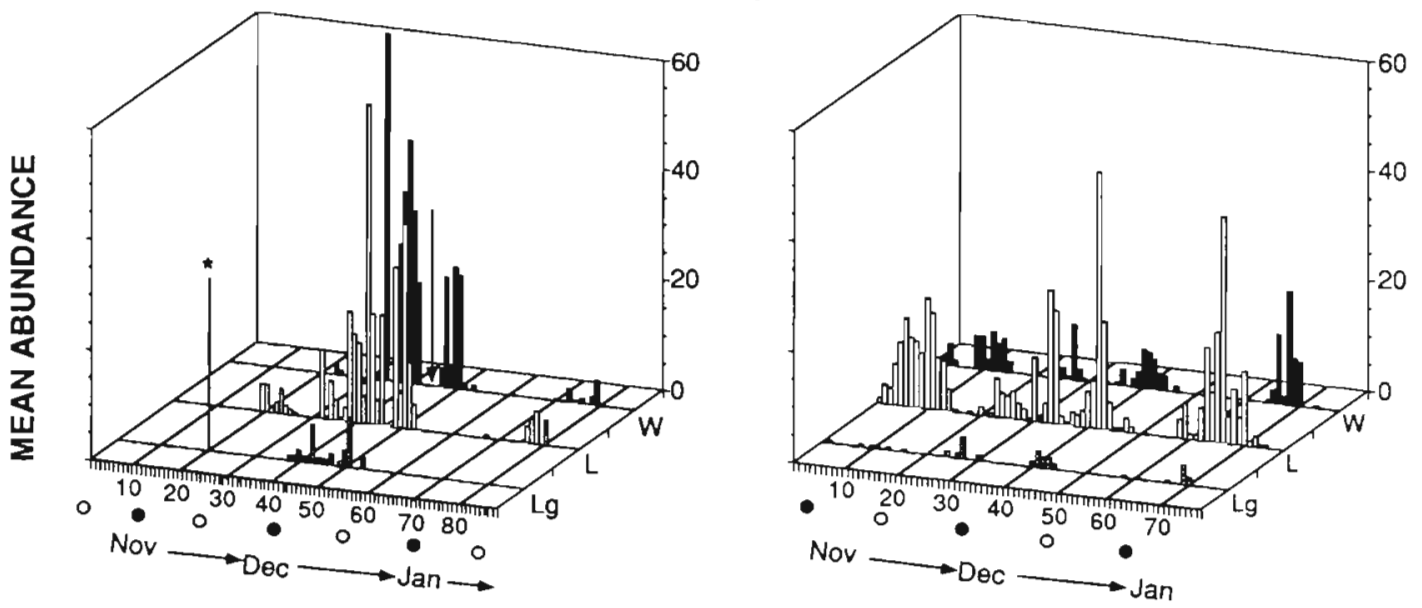

D. perspicillatus
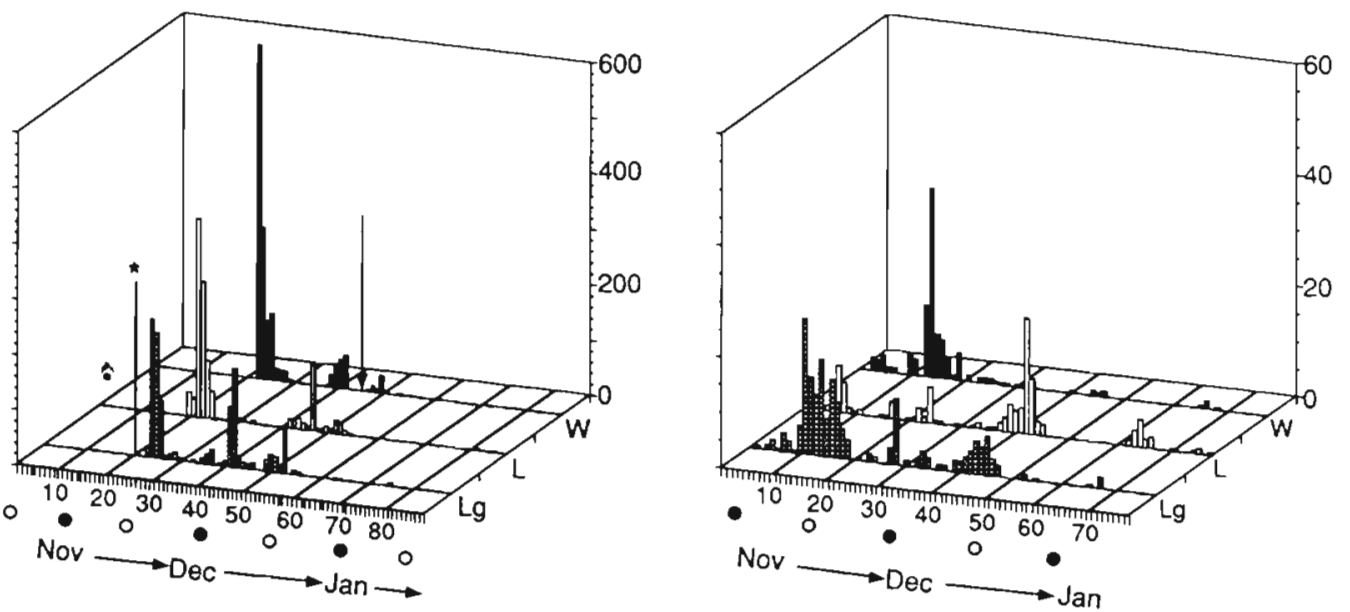

DAYS

Fig. 2. Pomacentrus amboinensis, $P$. nagasakiensis, Dischistodus perspicillatus. Mean daily abundance of pre-settlement fish in light traps, over both seasons for each species. W: windward habitat; L: leeward habitat; Lg: lagoonal habitat; $(\bullet)$ new moon; (o) full moon; $(\star)$ start of sampling in $1988 / 89$; ( $\downarrow$ ) 3 d period of trap failure in the windward habitat 
Table 1. Results of cross-correlation analyses for presettlement fish. The lag (in days) at which any 2 data sets correlate are given for different species/habitat combinations, in both sampling seasons. Pa: Pomacentrus amboinensis; Pn: P. nagasakiensis; Dp: Dischistodus perspicillatus; $\mathrm{L}$ : leeward habitat; $\mathrm{W}$ : windward habitat; Lg: lagoonal habitat. (-) non-significant correlations

\begin{tabular}{|c|c|c|}
\hline \multirow{2}{*}{$\begin{array}{l}\text { Species/habitat } \\
\text { combination }\end{array}$} & \multicolumn{2}{|c|}{ Lag of significant correlation in } \\
\hline & $1988 / 89$ & $1989 / 90$ \\
\hline \multirow{3}{*}{$\begin{aligned} \mathrm{Pa} & \times \mathrm{L} \times \mathrm{W} \\
& \times \mathrm{Lg} \times \mathrm{W} \\
& \times \mathrm{Lg} \times \mathrm{L}\end{aligned}$} & - & 2 \\
\hline & 0 & 0 \\
\hline & 1 & 0 \\
\hline \multirow{3}{*}{$\begin{aligned} \mathrm{Pn} & \times \mathrm{L} \times \mathrm{W} \\
& \times \mathrm{Lg} \times \mathrm{W} \\
& \times \mathrm{Lg} \times \mathrm{L}\end{aligned}$} & 0 & 0 \\
\hline & 0 & 1 \\
\hline & 0 & - \\
\hline \multirow{3}{*}{$\begin{aligned} D p & \times L \times W \\
& \times L g \times W \\
& \times L g \times L\end{aligned}$} & 1 & - \\
\hline & 1 & 0 \\
\hline & 2 & 4 \\
\hline \multirow{3}{*}{$\begin{aligned} W & \times \mathrm{Pa} \times \mathrm{Pn} \\
& \times \mathrm{Pa} \times \mathrm{Dp} \\
& \times \mathrm{Dp} \times \mathrm{Pn}\end{aligned}$} & 0 & 0 \\
\hline & - & 0 \\
\hline & - & - \\
\hline \multirow{3}{*}{$\begin{aligned} \mathrm{L} & \times \mathrm{Pa} \times \mathrm{Pn} \\
& \times \mathrm{Pa} \times \mathrm{Dp} \\
& \times \mathrm{Dp} \times \mathrm{Pn}\end{aligned}$} & 0 & - \\
\hline & - & 0 \\
\hline & - & 0 \\
\hline \multirow{3}{*}{$\begin{aligned} \mathrm{Lg} & \times \mathrm{Pa} \times \mathrm{Pn} \\
& \times \mathrm{Pa} \times \mathrm{Dp} \\
& \times \mathrm{Dp} \times \mathrm{Pn}\end{aligned}$} & 0 & 0 \\
\hline & 2 & 0 \\
\hline & 0 & 0 \\
\hline
\end{tabular}

contrast, abundance of settlement stage $P$. nagasakiensis was consistently low in the lagoonal habitat in each sampling year ( 4 and $5 \%$ of the total catch in each year respectively).

Comparing all species for the windward and leeward habitats from the 1988/89 season, it was clear that the pattern of abundance for Dischistodus perspicillatus was most different to the other 2 species, which were highly similar (Table 2). Pre-settlement fish of D. perspicillatus arrived in their greatest numbers $\mathrm{ca}$ 2 wk earlier than the 2 Pomacentrus species. This pattern was not so obvious in the second season. All species showed greater spread in their pattern of abundance throughout the season (hence greater overall synchrony), and the earlier appearance of $D$. perspicillatus was detected only in the windward habitat (Table 1, Fig. 2).

\section{Post-settlement}

Inter-annual changes in the magnitude of recruitment were similar to the trends identified from the light trap data: overall abundance of Dischistodus perspicillatus dropped by $73 \%$ and of Pomacentrus amboinensis by $30 \%$, while total numbers of $P$. nagasakiensis remained about the same $(91$ compared to 87) (Fig. 3) Statistics and probabilities for tests of
Table 2. Statistics for post-settlement data testing $H_{0}$ : data sets are independant; between habitats for each species, and species for each habitat. "significant at 0.05 level. Other symbols as in Table 1

\begin{tabular}{|ccccc|}
\hline Season & Species & Habitat & $\overline{\mathrm{r}}$ & $\lambda_{1} / \mathrm{p}$ \\
\hline $1988 / 89$ & $\mathrm{~Pa}$ & All & 0.275 & 0.526 \\
& Pn & All & $0.925^{\circ}$ & $0.950^{\circ}$ \\
& Dp & All & 0.454 & 0.675 \\
& All & W & 0.304 & 0.621 \\
& All & L & 0.291 & 0.605 \\
& All & Lg & 0.135 & 0.438 \\
$1989 / 90$ & Pa & All & $0.726^{\circ}$ & $0.821^{\circ}$ \\
& Pn & All & $0.536^{\circ}$ & 0.695 \\
& Dp & All & 0.425 & 0.627 \\
& All & W & 0.248 & 0.537 \\
& All & L & 0.339 & 0.623 \\
& All & Lg & 0.323 & 0.613 \\
\hline
\end{tabular}

independance among habitats for each species and among species for each habitat are given in Table 2. In the first season of sampling, recruitment of $P$. amboinensis and $D$. perspicillatus was asynchronous among the habitats, but for $P$. nagasakiensis, recruitment was similarly timed in all habitats (Fig. 3). During the second season of sampling both $P$. nagasakiensis and $P$. amboinensis exhibited synchrony among habitats, while for $D$. perspicillatus, the low numbers in the windward and leeward habitats suggested that differences in the timing of recruitment among habitats was of little consequence. The consistently low numbers of $P$. nagasakiensis recruits in the lagoon was as strong a feature of the recruitment data as that of the pre-settlement data, in both years.

In the $1988 / 89$ season, recruitment among species was asynchronously timed in all habitats (Table 2). As for the light trap data, this was mostly due to the earlier recruitment of Dischistodus perspicillatus compared to the other species (Fig. 3). In the following year, the same pattern emerged with recruitment of $D$. perspicillatus again appearing to be earlier than the other species.

\section{Comparison of pre-settlement and post-settlement distributions}

The abundance of pre-and post-settlement fish were significantly correlated when all species were combined across both sampling years and habitats (Table 3 ). For each species taken separately but pooled across all habitats, a significant correlation was also detected with the exception of Pomacentrus amboinensis in the 1989/90 season (Table 3, Fig. 4). 
$1988 / 89$

P. amboinensis

$1989 / 90$
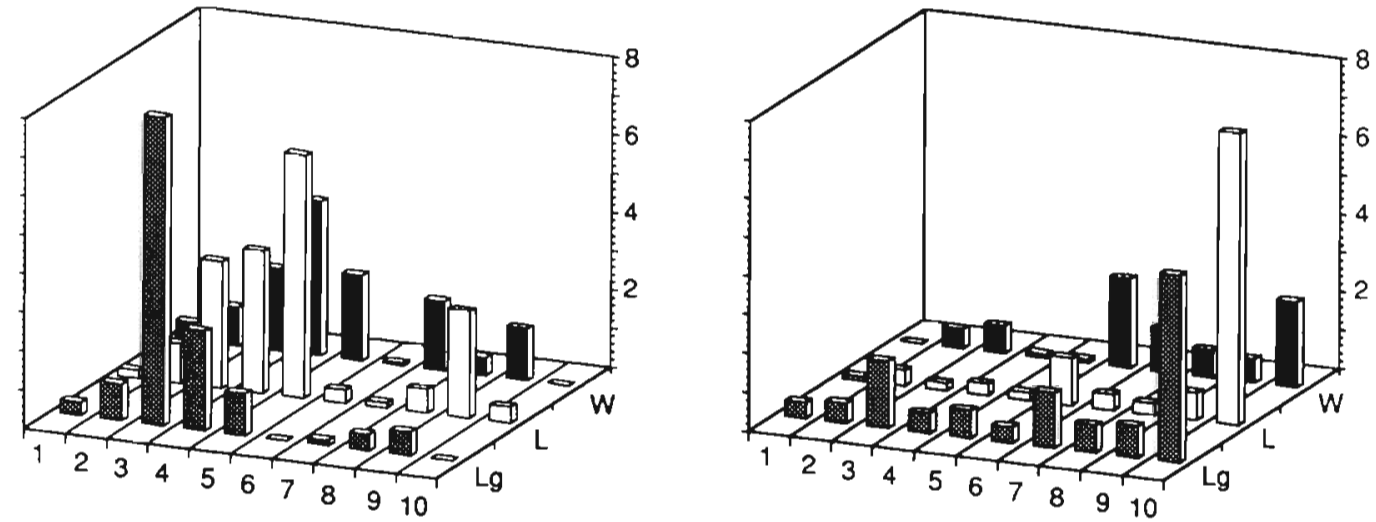

P. nagasakiensis
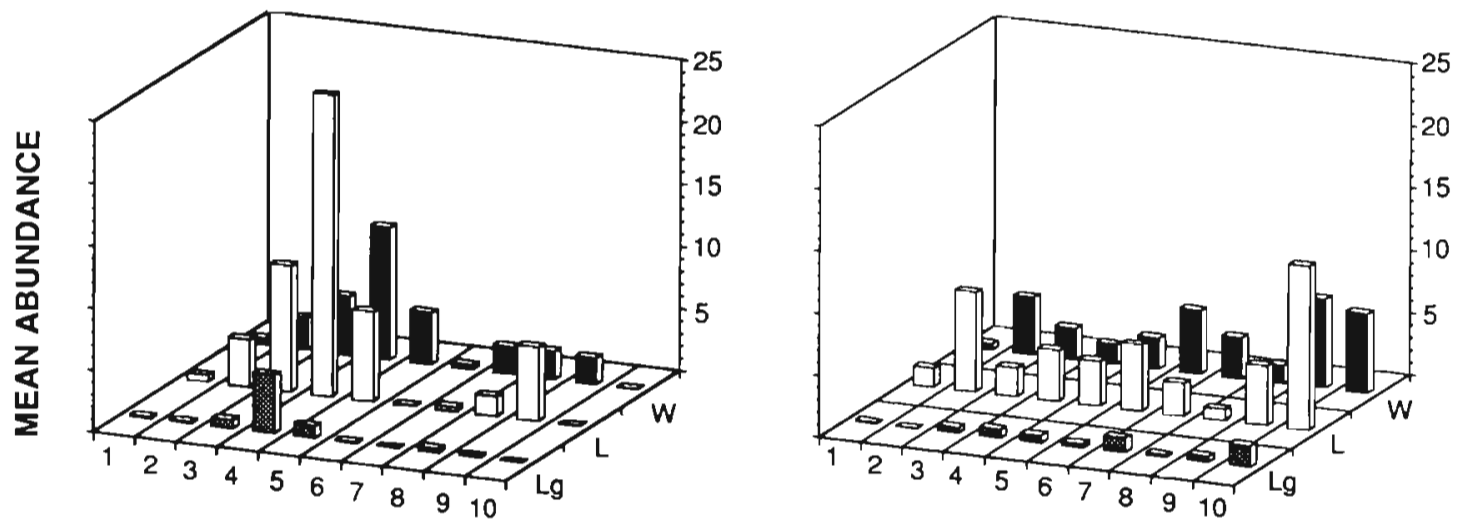

D. perspicillatus
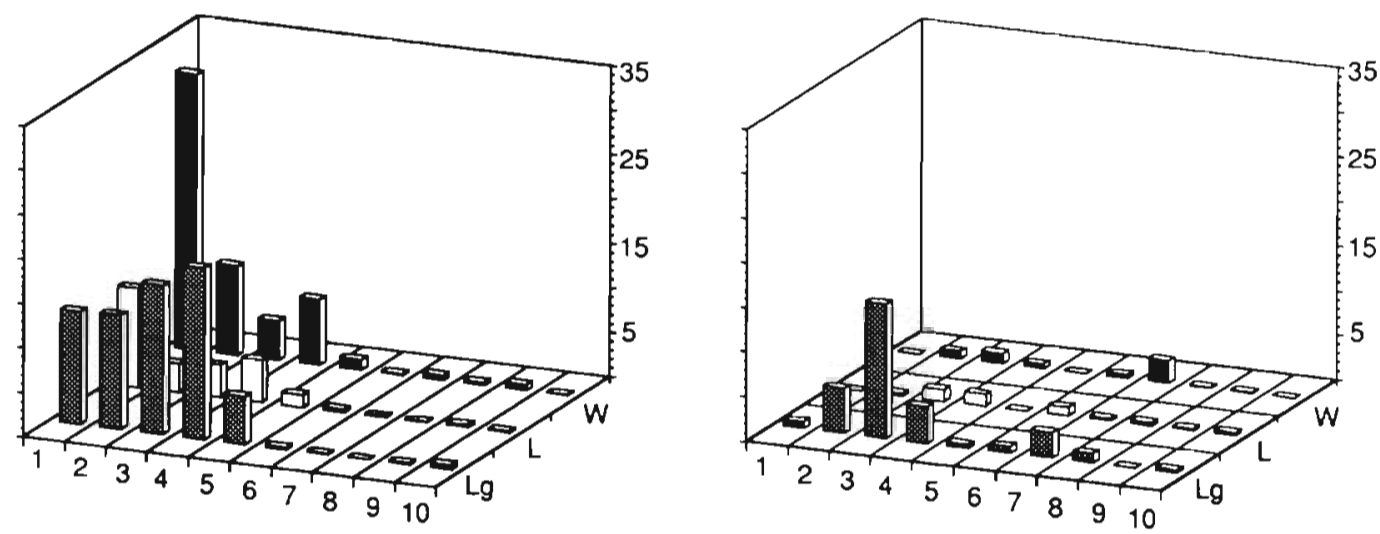

WEEKS

Fig. 3. Pomacentrus amboinensis, $P$. nagasakiensis, Dischistodus perspicillatus. Mean weekly abundance of post-settlement fish collected from patch reefs, over both seasons for each species. W: windward habitat; L: leeward habitat; Lg: lagoonal habitat 
Table 3. Mean correlations ( $\bar{r})$ and largest eigenvalues $\left(\lambda_{1} / p\right)$ between pre-and post-settlement fish distributions, pooled across species, in each season. $r$ : the correlation for each species in isolation. ' significant at 0.05 level. Other symbols as in Table 1

\begin{tabular}{|ccccc|}
\hline Season & Species & $\bar{r}$ & $\lambda_{1} / \mathrm{p}$ & $\mathrm{r}$ \\
\hline $1988 / 89$ & $\mathrm{~Pa}$ & & & $0.667^{\circ}$ \\
& $\mathrm{Pn}$ & $0.665^{\circ}$ & $0.351^{\circ}$ & $0.570^{\circ}$ \\
& $\mathrm{Dp}$ & & & $0.747^{\circ}$ \\
$1989 / 90$ & $\mathrm{~Pa}$ & & & $0.280^{\circ}$ \\
& $\mathrm{Pn}$ & $0.495^{\circ}$ & $0.397^{\circ}$ & $0.593^{\circ}$ \\
& $\mathrm{Dp}$ & & & $0.613^{\circ}$ \\
\hline
\end{tabular}

When the level of this comparison was narrowed to the habitat scale, more variability was observed in the relationship between pre- and post-settlement distributions. The power of these comparisons was consistently high, with a mean power across all habitat/ species combinations of $0.846 \pm 0.03 \mathrm{SE}$. For the $1988 / 89$ season, significant linear relationships existed for Pomacentrus amboinensis from both the leeward and lagoonal localities $\left(\mathrm{r}^{2}=0.66,0.82\right.$ respectively), but no relationship was apparent for the windward habitat (Fig. 5). In addition, the slopes of the relationships for the leeward and lagoonal habitats differed (ANCOVA, $p=0.04$ ) (Fig. 5). Only the leeward locality returned a strong relationship between pre- and postsettlement distributions in P. nagasakiensis $\left(\mathrm{I}^{2}=0.94\right)$ (Fig. 5), while for Dischistodus perspicillatus strong but different relationships existed in the windward and leeward $\left(\mathrm{r}^{2}=0.89,0.93\right.$ respectively, ANCOVA, $p=0.005$ ) (Fig. 5), but not lagoonal habitats.

In the following season of sampling, when numbers of Pomacentrus amboinensis and Dischistodus perspicillatus were considerably lower, positive relationships between light trap and patch reef patterns were much less evident (Figs. 4 \& 5). A significant linear relationship between pre-settlement and post-settlement patterns of abundance was detected in only one habitat for 2 of the species (windward for $P$. nagasakiensis and lagoon for $D$. perspicillatus) $\left(\mathrm{r}^{2}=0.52\right.$, 0.60 respectively) (Fig. 5).

\section{DISCUSSION}

Until recently, the technology has not been available to adequately describe distribution patterns of late presettlement fish directly, and claims of a relationship between pre- and post-settlement fish distributions have been purely inferential, based on detailed analysis of recruited fish distributions. However, such patterns are unalterably confounded with other influences including habitat selection (Sweatman 1983,
1985, Jones 1987), post-settlement predation (Doherty \& Sale 1986, Eckert 1987, Hixon \& Beets 1989) and competition (Jones 1987, 1991).

Previous claims (Doherty 1983c, Williams 1986) notwithstanding, the relative importance of these processes cannot be determined without quantitative sampling of larval supply. Victor (1986) attempted to estimate the availability of bluehead wrasse larvae in the plankton by dip-netting reef fish larvae attracted at night to a submerged light. He found a significant correlation between the number of species of fish larvae attracted to the light and the number of larvae captured in plankton tows during the same night, although absolute abundance levels were low (range: 0 to 11 per $100 \mathrm{~m}^{3}$ ). However, bluehead wrasse larvae were rarely caught by either technique and he was forced to assume that the intensity of wrasse settlement was directly related to the number of species of larvae captured at the night-light, despite admitting that these samples were occasionally dominated by large numbers of single species. Using this indirect approach, Victor claimed that there was a strong correlation between the diversity of night-light captures and the numbers of bluehead wrasse juveniles that appeared on the reef 5 d later. Even though Victor obtained a correlation coefficient of only 0.27 (i.e. explaining $<15 \%$ of the variance), he concluded that the intensity of settlement reflected the availability of larvae in the water passing over the reef.

The development of the automated light-trap, as used in the present study, has conferred several advantages to investigations of patterns in larval supply. Both Doherty (1987) and Milicich $(1988,1992)$ have shown that light-traps are capable of collecting large numbers of settlement stage fish of a wide range of taxa. The automation of the gear allows the monitoring of larval supply almost continuously over time at a range of locations. This allows us to replicate sampling and so quantify, for the first time, spatial and temporal patterns in the abundance of potential settlers

In this study, catches were quantified to numbers per day of sampling. This unit will be a valid currency for comparing catches if factors which affect the efficiency of the traps do not vary widely between nights and/or habitats. Fluctuations in turbicity levels and current velocities are 2 of the most obvious factors that may be expected to bias catch estimates (Milicich 1992). Shortterm turbidity changes have been measured at Lizard Island, and the results suggest that lagoonal water was consistently the most turbid, while clarity in the windward and leeward habitats appeared to change only after substantial periods of calm weather (Milicich. 1992). In the present study, calm seas seldom lasted more than a few days. Sampling times were staggered to minimise effects of current flow, and a comparison of 
$1988 / 89$

P. amboinensis

$1989 / 90$
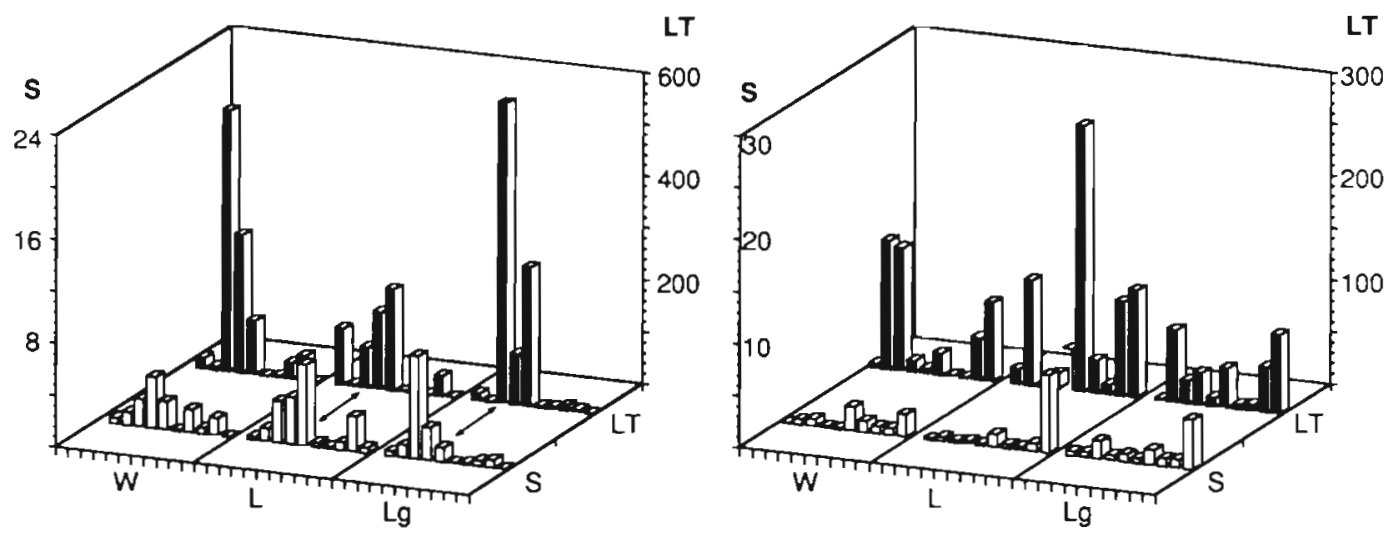

\section{P. nagasakiensis}
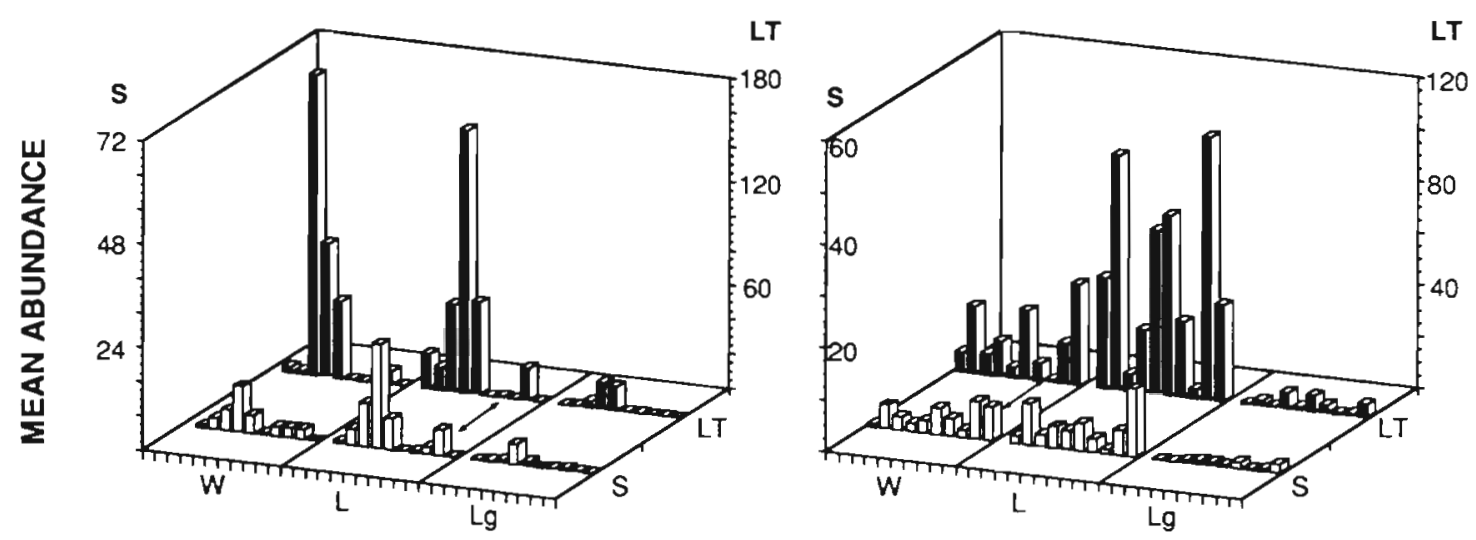

\section{D. perspicillatus}

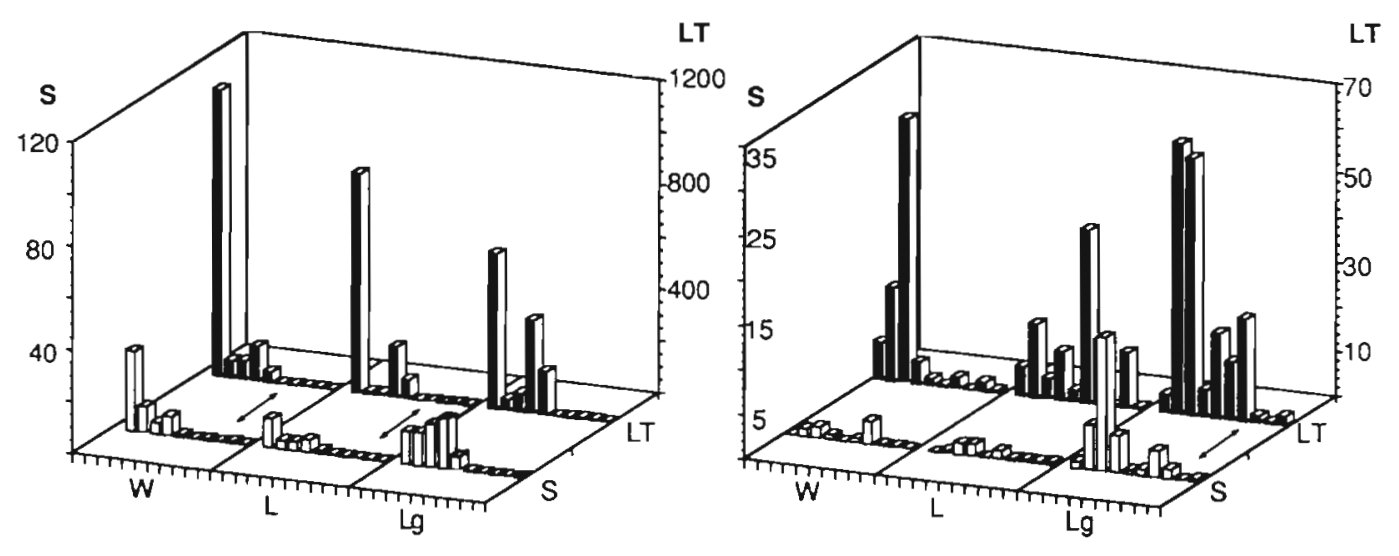

\section{WEEKS}

Fig. 4. Pomacentrus amboinensis, P. nagasakiensis, Dischistodus perspicillatus. Mean weekly abundance of pre-settlement (1L) and post-settlement (S) fish in the 3 habitats, over both seasons for each species. $W$ windward habitat; L: leeward habitat; Lg: lagoonal habitat; ( ) significant relationships (see also Fig. 5) 


\section{$1988 / 89$}

P. amboinensis

$1989 / 90$

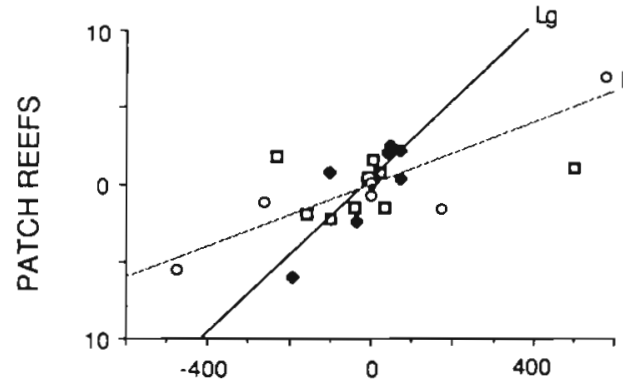

LIGHT TRAPS

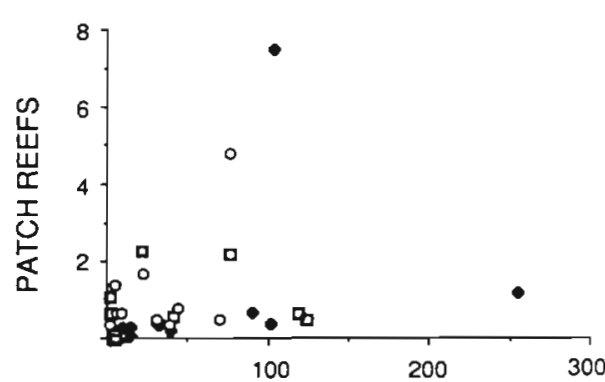

LIGHT TRAPS

P. nagasakiensis

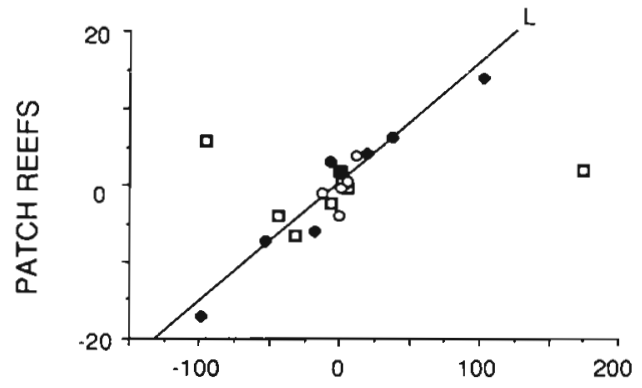

LIGHT TRAPS

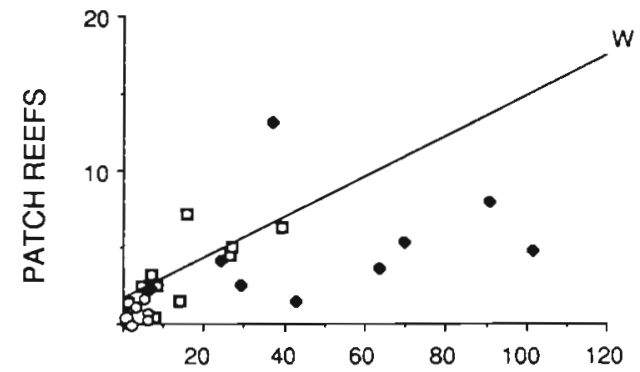

LIGHT TRAPS

\section{D. perspicillatus}

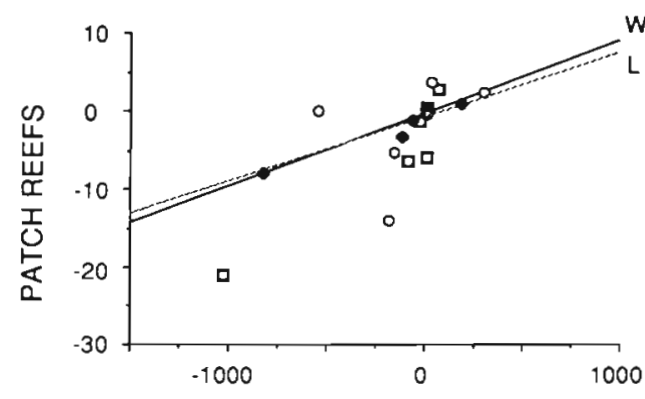

LIGHT TRAPS

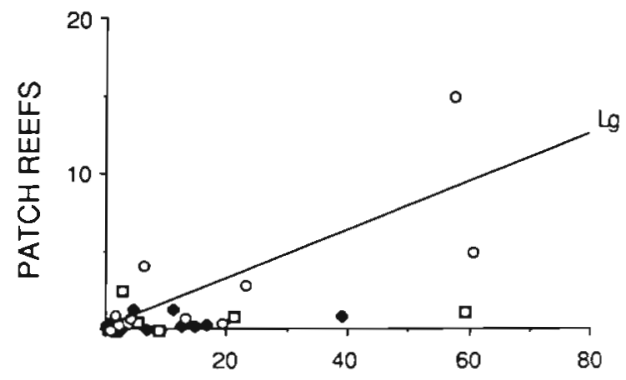

LIGHT TRAPS

Fig. 5. Pomacentrus amboinensis, P. nagasakiensis, Dischistodus perspicillatus. Regression plots of pre- vs post-settlement weekly abundance for the $1988 / 89$ and $1989 / 90$ seasons. Data for $1988 / 89$ have been first-differenced, i.e. value is subtracted from following value (see 'Methods'). This removes autocorrelation from the data and can lead to negative values. Significant regression relationships are identified on the plots by straight lines. W, $\square$ : windward habitat; $L_{1} \bullet$ : leeward habitat; Lg, 0 : lagoonal habitat. $\mathrm{r}^{2}$ values and equations for the significant relationships are as follows: $P$. amboinensis $1988 / 89 \mathrm{Lg}, y=0.01 x-0.021$, $\mathrm{r}^{2}=0.82 ;$ P. amboinensis $1988 / 89 \mathrm{~L}, y=0.025 x+0.320, \mathrm{r}^{2}=0.66 ; P$. nagasakiensis $1988 / 89 \mathrm{~L}, y=0.155 x+0.285, \mathrm{r}^{2}=0.94 ;$ D. perspicillatus $1988 / 89 \mathrm{~W}, y=0.020 x-1.04, \mathrm{r}^{2}=0.89 ;$ D. perspicillatus 1988/89 L, $y=0.009 x-0.348, \mathrm{r}^{2}=0.93 ; P$. nagasakiensis $1989 / 90 \mathrm{~W}, y=0.132 x+1.572, \mathrm{r}^{2}=0.52 ;$ D. perspicillatus $1989 / 90 \mathrm{Lg}, y=0.156 x+0.095, \mathrm{r}^{2}=0.60$ 
catches taken at different times of the night over $8 \mathrm{~d}$ suggest that no consistent tidal effect was present (P. J. Doherty unpubl.). Non-tidal flow at Lizard Island is driven by the wind which will fluctuate and alter the amount of water sampled by the light traps. However, the light traps were placed between pre-settlement fish and their final destination, and from this perspective, changes in abundance as a result of changes in water flow are less of a problem than they are a focus of interest. If catches respond to wind stress, stronger onshore winds may also be expected to increase recruitment rates, making the comparison between light traps and patch reefs no less valid than if the wind had no effect.

This study has shown that at a general multispecific and reefal scale, distribution patterns of 3 species of pre-settlement fish were highly correlated with subsequent recruitment patterns. This is the first conclusive evidence that early recruitment patterns of coral reef fish may be determined by larval supply despite the mediating influences of processes such as habitat selection and post-settlement mortality.

This finding has important ramifications for the study of coral reef fish populations. As post-settlement mortality is often at its greatest during the first week after settlement (Doherty \& Sale 1986) positive correlations between pre- and post-settlement distributions suggest that variations in larval replenishment may exert long-term influences over the abundance and demography of benthic populations. A number of previous studies have shown that spatial and temporal patterns in recruitment are preserved over months (Pitcher 1988) and years (Williams 1979, Victor 1983) and Doherty \& Fowler (unpubl.) have shown that interannual variations in year-class strength at reef-wide scales can be preserved in age-structures for at least a decade. This study closes the early life history and demonstrates that these recruitment patterns can be determined by processes operating before settlement, a result that is consistent with the predictions of the recruitment-limitation hypothesis (Doherty \& Williams 1988). Collectively these studies support the use of recruitment surveys as tools for forecasting the supply of recruits to future breeding populations and hindcasting variations in larval supply (Doherty 1983c).

Despite some loss of information inherent in this survey technique, the logistics of attempting to monitor replenishment of fish populations over large scales (10's to 1000 's km) may mean that annual recruitment surveys pose the only viable solution. Pitcher (1988) showed that the information content of recruitment surveys can be expanded by back-calculations of otolith data to reveal the temporal history of year-class formation. What is required to increase confidence in these measurements is repetition of studies like the present one.
The major value of the light traps will be in mapping the abundance of late pre-settlement fish over spatial scales of 20 to $200 \mathrm{~km}$ which appears to be an important scale for the generation of recruitment variability. From previous descriptions of recruitment patterns, several researchers have suggested that presettlement fish may be distributed in meso-scale (10 to $100 \mathrm{~km}$ ) patches in the pelagic environment with major recruitment events being realised from the occasional collision of these heterogenous patches with suitable reefal habitat (Victor 1984, Doherty 1987, Pitcher 1987 , Doherty \& Williams 1988). Further investigation of this phenomenon awaits detailed descriptions of the way pre-settlement fish are distributed around and away from reefs and some of these are in progress (Milicich 1992, Doherty unpubl.). However, the occasional discordance in the synchrony of pre-settlement fish among habitats revealed in this study, suggests that these patches, if they exist, will not always be distributed across reefs in the same way for each replenishment event.

Although pre-settlement patterns were correlated to recruitment patterns at the scale of Lizard Island for all but one species/season combination (Pomacentrus amboinensis/second year), the correlation was generally poor at the habitat level; significant linear relationships between light traps and patch reefs were found for only 7 out of a possible 18 habitat/species combinations. This small-scale mismatch between light trap catches and patch reef collections could be due to biological factors, random effects, or alternatively, biases and errors in the sampling methodologies.

Perhaps the simplest explanation is that it is unrealistic to expect the pre-and post-settlement patterns to converge at this spatial scale when each technique is attempting to cover a considerable portion of both the pelagic and benthic habitats with a small number of replicates. Of the 7 significant regressions detected, only 2 came from the second year of sampling. This breakdown may have been due in part to the difficulty of detecting pattern from the background noise when recruitment levels to individual habitats were so low. The fact that there was a significant relationship for Dischistodus perspicillatus in the lagoon supports this, as the numbers settling in this habitat were proportionately much higher than in the other 2 habitats. However, it does not explain the lack of coincidence for Pomacentrus amboinensis where high numbers of pre-settlement fish were captured but were not correlated with the post-settlement patterns. Similarly, the relationship between pre- and post-settlement abundance for P. nagasakiensis broke down in the second year even though abundances were similar in the two years. For the leeward habitat, the lack of coincidence was attributable to events occurring during a single week of sampling. 
If the effect was due to bias in sampling methodology, it must be a variable one since the breakdown in the concordance of the patterns of fish abundance was variable among habitats, years and species. It is likely that fish caught in the light traps encompass individuals with a range of settlement capabilities but one would not expect this and associated parameters (e.g. size, age) to vary by more than a few days. Thorrold \& Milicich (1990) investigated age and size at settlement for 2 other pomacentrid species (Pomacentrus coelestis and Chromis atripectoralis) collected from light traps. Although ages of $P$. coelestis varied between the widely separated sampling locations (ca $500 \mathrm{~km}$ apart), within any location the ages of both species were concentrated in a relatively narrow range (up to $80 \%$ individuals in a $3 \mathrm{~d}$ range). This characteristic makes it unlikely that more than a few percent of the fish collected by the light traps in any week were wrongly allocated to that week's total, based on the criterion of settlement competency. In addition, there was no evidence of any time delay between the input of fish to the nearshore waters and the recruitment of fish to benthic habitats. Finally, the inherent patchiness of pre-settlement fish dictates that chance encounters with light traps will result in high variability in catch rates on any one day (Milicich 1992). This effect has been averaged across sampling days and replicates and therefore has been minimised although as the comparison shifts to smaller spatial scales this effect would be magnified. For much of the time in the first season there was only one trap operating in the lagoon. This lack of replication might be expected to favour a discordance between light traps and patch reefs, however for one species ( $P$. amboinensis) there was a significant relationship between pre and post-settlement patterns in this habitat. Furthermore, the windward and lagoonal habitats had the same number of nonsignificant relationships.

Weekly collections of fish were used to estimate patterns of recruitment in this study. Although the results of this study suggest that post-settlement processes such as predation and competition did not significantly alter the relative pattern of initial settlement at the scale of Lizard Island, these processes may become important at smaller scales. Relative magnitudes of mortality are known to vary among years and among species in the same habitat (Doherty \& Sale 1985, Aldenhoven 1986, Eckert 1987, but see Meekan 1988). Such changes may have contributed to the general failure of pre-settlement Pomacentrus amboinensis to correlate with recruited fish in the second year. However, no information is available on species-specific mortality among habitats during the first week after settlement. Since mortality during this time can rise as high as $40 \%$ (Sale \& Ferrell 1988), small but random changes may result in significant changes in relative numbers and provide an explanation for the decoupling of pre-settlement and postsettlement patterns at the habitat level (Warner \& Hughes 1988). In support of this, Hixon \& Beets (1989) showed that turnover on small reefs was highly variable and related to the prescence/absence of resident predators.

A further advantage in assessing the link between the patterns of pre- and post-settlement fish using this technique is that it allows habitat selection at a large spatial scale to be investigated independantly of any micro-habitat effects (e.g. Sweatman 1983. 1985, Sale et al. 1984b, Victor 1986). Evidence for habitat selection from our study comes from 2 species in the first year of sampling. For Pomacentrus amboinensis significant differences in the slope of the relationship between pre- and post-settlement distributions were found between the leeward and lagoonal habitats. Interpretation of this result at face value suggests that settlement stage $P$. amboinensis may preferentially choose the leeward habitat at settlement. In a similar way analysis of the same relationship for the leeward and windward habitats for Dischistodus perspicillatus suggests that these fish settle in a higher proportion to the windward as compared to the leeward locality than would be predicted from the distributions of pre-settlement fish. Closer inspection reveals that these differences were probably the result of events occurring over a couple of weeks within the season (see Fig. 4). This pattern of a few highly episodic replenishment events in any season is a characteristic of many fish populations that have been studied on the GBR. For this reason, daily settlement censuses would increase the number of points in any correlation and increase confidence in the significance of these tests. Such an approach would allow questions about habitat selection to be addressed more appropriately.

In summary this study shows that at the scale of a single reef over 2 consecutive recruitment seasons, the abundance of settlement stage fish was a good predictor of the abundance of recruits of 3 pomacentrid species. In the present study, this suggests that spawning events and/or planktonic processes largely determine at least the early stages of recruitment events. At smaller temporal and spatial scales, sampling methodology and error, habitat selection and early mortality may act to decouple this relationship. As the scales of major human interest are management of whole reef units and effects due to interannual variability in year-class size, recruitment surveys can be expected to provide important information about the scales of processes that determine replenishment variability. 
Acknowledgements. This study was undertaken when M.J.M. and M.G.M. were supported by Griffith University Postgraduate Scholarships and M.J.M. was a recipient of a Lizard Island Research Fellowship. We also acknowledge further financial support from the Australian Institute of Marine Science, the Australian Coral Reef Society and the Great Barrier Reef Marine Park Authority. We thank D. Grice, L. McIlwain, A. McNicol, K. Milicich and J Murdoch for assistance in the field, $\mathrm{S}$. Thorrold and 2 reviewers for their helpful comments.

\section{LITERATURE CITED}

Aldenhoven, A. J. (1986). Local variation in mortality rates and life-expectancy of the coral-reef fish Centropyge bicolor (Pisces: Pomacanthidae). Mar. Biol. 92: 237-244

Box, G. E. P., Jenkins, G. M. (1976). Time series analysis, forecasting and control. Holden-Day, San Francisco

Chatfield. (1984). The analysis of time series: an introduction. Chapman and Hall, London

Choat, J. H., Doherty, P. J., Kerrigan, B. A., Leis, J M. (in press). Presettlement stages of coral reef fishes: an evaluation of six sampling devices. Fish. Bull. U.S.

Doherty, P. J. (1983a). Diel, lunar and seasonal rhythms in the reproduction of two tropical damselfishes: Pomacentrus flavicauda and $P$. wardi. Mar. Biol. 75: 215-224

Doherty, P. J. (1983b). Tropical territorial damselfishes: is density limited by aggression or recruitment? Ecology 64: $76-90$

Doherty, P. J. (1983c). Recruitment surveys of coral reef fishes as tools for science and management. In: Baker, J. T., et al. (eds.) Proc. of the Inaugural Great Barrier Reef Conf. JCU Press, Townsville, p. 191-196

Doherty, P. J. (1987). Light traps: selective but useful devices for quantifying the distributions and abundances of larval fishes. Bull mar. Sci. 41(2): 423-431

Doherty, P. J. (1991). Spatial and temporal patterns in recruitment. In: Sale, P. F. (ed.) Ecology of fishes on coral reefs. Academic Press, New York, p. 261-292

Doherty, P. J., Sale, P. F. (1986). Predation on juvenile coral reef fishes: an exclusion experiment. Coral Reefs 4: $225-234$

Doherty, P. J., Williams, D. McB. (1988). The replenishment of coral reef fish populations. Oceanogr. mar. Biol. A. Rev. 26: $487-551$

Eckert, G. J. (1987). Estimates of adult and juvenile mortality for labroid fishes at One Tree Reef, Great Barrier Reef. Mar. Biol. 95: 167-171

Hixon, M. A., Beets, J. P. (1989). Shelter characteristics and Caribbean fish assemblages: experiments with artificial reefs. Bull. mar. Sci 44(2): 666-680

Houde, E. D., Leak, J. C., Dowd, C. E., Berkely, S. A. (1979). Ichthyoplankton abundance and diversity in the eastern Gulf of Mexico. Final Rep. Bur. Land Mgmt Contr. AA550CT7-28. NTIS-PB-299839. Bureau of Land Management, Washington, D.C.

Jones, G. P. (1987). Some interactions between residents and recruits in two coral reef fishes. J. exp. mar. Biol. Ecol. 114: $169-182$

Jones, G. P. (1991). Postrecruitment processes in the ecology of coral reef fish populations: A multifactorial perspective. In: Sale, P. F. (ed.) Ecology of fishes on coral reefs. Academic Press, New York, p. 294-347

Leis, J. M. (1986). Vertical and horizontal distribution of fish larvae near coral reefs at Lizard Island, Great Barrier Reef. Mar. Biol. 90(4): 505-516
Leis, J. M., Goldman, B., Reader, S. E. (1989). Epibenthic fish larvae in the Great Barrier Reef Lagoon near Lizard Island, Australia. Jap. J. Ichthyol. 35(4): 423-433

Le1s, J. M. Miller, J. M. (1976). Offshore distributional patterns of Hawaiian fish larvae. Mar. Biol. 36: 359-367

Leis, J. M. Rennis, D. S (1983). The larvae of Indo-Pacific coral reef fishes. New South Wales University Press, Sydney, and University of Hawaii Press, Honolulu

Meekan, M. G. (1988). Patterns of settlement and mortality of juvenile reef fishes at Lizard Island, northern Great Barrier Reef. In: Choat, J. H. et al. (eds.) Proc. 6th int. coral Reef Congr. 2: 779-784

Milicich, M. J. (1988). The distribution and abundance of presettlement fish in the nearshore waters of Lizard Island. In: Choat, J. H. et al. (eds.) Proc. 6th int. coral Reef Congr. 2: $785-790$

Milicich, M. J. (1992). Light traps: a novel technique for monitoring larval supply and replenishment of coral reef fish populations. Ph.D. thesis, Griffith Univ.

Pitcher, C. R. (1987). Validation and application of otolith ageing techniques to some problems in the ecology of coral reef fishes. Ph.D. thesis, Griffith Univ.

Pitcher, C. R. (1988). Validation of a technique for reconstruction of daily patterns in the recruitment of coral reef damselfish. Coral Reefs 7:105-111

Robertson, D. R., Green, D. G., Victor, B. C. (1988). Temporal coupling of production and recruitment of larvae of a Caribbean reef fish. Ecology 69(2): 370-381

Sale, P. F. (1985). Patterns of recruitment in coral reef fishes. In: Gabrie, C., et al. (eds.) Proc. 5th int. coral Reef Congr. 5: $391-396$

Sale, P. F., Doherty, P. J., Eckert, G. J., Douglas, W. A., Ferrell, D. J. (1984a). Large scale spatial and temporal variation in recruitment to fish populations on coral reefs. Oecologia 64: $191-198$

Sale, P. F., Douglas, W. A., Doherty, P. J (1984b). Choice of microhabitats by coral reef fishes at settlement. Coral Reefs. 3: $91-99$

Sale, P. F., Ferrell, D. J. (1988). Early survivorship of juvenile coral reef fishes. Coral Reefs 7: 117-124

Sweatman, H. P. A. (1983). Influence of conspecifics on choice of settlement sites by larvae of two pomacentrid fishes (Dascyllus aruanus and D. reticulatus) on coral reefs. Mar. Biol. 75: 225-229

Sweatman, H. P. A. (1985). The influence of adults of some coral reef fishes on larval recruitment. Ecol. Monogr 55 $469-485$

Thompson, K. R., Page, F. H. (1989). Detecting synchrony of recruitment using short, autocorrelated time series. Can. J. Fish. Aquat. Sci. 46: 1831-1838

Thorrold, S. R., Milicich, M. J. (1990). Comparison of larval duration, and pre- and post-settlement growth in two species of damselfish (Pisces: Pomacentridae) from the Great Barrier Reef. Mar. Biol 105: 375-384

Thresher, R. E. (1984). Reproduction in reef fishes. THF Publications, New Jersey

Victor, B. C. (1983). Recruitment and population dynamics of a coral reef fish. Science 219: 419-420

Victor, B. C. (1984). Coral reef fish larvae: patch size estimation and mixing in the plankton, Limnol. Oceanogr. 29(5): $1116-1119$

Victor, B. C. (1986). Larval settlement and juvenile mortality in a recruitment limited coral reef fish population. Ecol. Monogr. 56: 146-160

Warner, R. R., Hughes, T P. (1988). The population dynamics of reef fishes. In: Choat, J. H. et al. (eds.) Proc. 6th int. coral Reef Congr. 1: 149-155 
Williams, D. McB (1979). Factors influencing the distribution and abundance of pomacentrids (Pisces: Pomacentridae) on small patch reefs in the One Tree lagoon (GBR). Ph.D thesis, Sydney Univ.

Williams, D. McB. (1983). Daily, monthly and yearly variability in recruitment of a guild of coral reef fishes. Mar. Ecol. Prog. Ser. 10: 231-237

Williams, D. McB. (1986). Spatial and temporal scales of processes determining inter-annual variation in recruit-

This article was presented by D. Klumpp, Townsville, Queensland, Australia ment of fishes of the Great Barrier Reef: some preliminary data. IOC Workshop Rep. 44 (suppl.): 229-239

Williams, D. McB., Sale, P. F. (1981). Spatial and temporal patterns of recruitment of juvenile coral reef fishes to coral habitats within 'One Tree Lagoon', Great Barrier Reef. Mar. Biol. 65: 245-253

$Z_{2}$ J. H. (1984). Biostatistical analysis. Prentice-Hall, Englewood Cliffs

Manuscript first received: December 9, 1991

Revised version accepted: July 23, 1992 